\title{
Research on the Students' Psychological Health Evaluation Management System
}

\author{
Li Dai, Qi Lu, Mei Lin, Li Xu \\ Department of Management Science \& Engineering \\ Zhejiang Sci-Tech University \\ Hangzhou, China \\ dl@zstu.edu.cn
}

\begin{abstract}
This article is a basic prevention and control policy of psychological problems for college students based on Zhejiang province education department in China. It uses the PHP program technology to develop a management system on students' mental health. It mainly aims to apply the psychological counsel and test for students through the online system, and the teachers get the psychological test results from the platform, even the mental health counseling to students and then follow up an appointment to educate students. Through this platform, teachers can easily master the mental health situation of all the students, and students are also more easily to interact with teachers for psychological guidance, after that teachers carry out the relevant work and finally alleviate or solve some students' psychological health problems.
\end{abstract}

Keywords-psychological health; psychological evaluation; psychological counseling; PHP; questionnaire

\section{INTRODUCTION}

With the rapid development of society, it constantly puts forward higher requirements to the college students' psychological quality; most freshmen don't know how to deal with things. Due to lack of the relevant courses at colleges on guiding the freshmen's psychological education, it easily leads to more or less psychological problems for most students, and this phenomenon becomes more serious.

College students' psychological health problems are outstanding, but the management and application of mental health archives are relatively backward. Colleges and universities have high-quality professional teacher's teams, and the popularity of computer and network technology provides professional knowledge security and technical support for the improvement and development of psychology health archives management [1]. Psychological archives break the previous subjective consciousness of teachers and parents to evaluate students' acts liking the "roll archives" and "physical examination archives", they will not only develop the students' potential and offer the conditions for the cultivation and enhancement of students' psychological quality, but also provide a guarantee for teachers' psychological counseling [23].

To strengthen the construction of teaching staff of psychological health management and speed up the archives

This research was financially supported by: The " 521 personnel train ing plan” of Zhejiang Sci-Tech University, Applied Economics Research Base of Zhejiang Sci-Tech University (2016JYJG03), Project funded by China Postdoctoral Science Foundation and China Scholarship Council. system development of college students’ psychological health, this paper deeply digs into the application value of college students' psychological archives, establishes the growth and psychological health records, which are the effective ways to improve and develop the psychological health archives management of college students at present.

\section{SYSTEM ANALYSIS}

As one of the important part of college teaching management, the main object of the system is to provide the students' psychological health information more timely, conveniently and comprehensively for the tutors, and facilitates the overall management. At the same time, it provides a safe and convenient platform for advisory psychological problems of the students [4].

\section{A. The system target}

This article realizes a psychological health management, its main functions is to collect the data of students' psychological tests, then teachers use them to complete the classification statistics on students' psychological situation and provide students for a platform of reservation for psychological consultation and message consultation online. The users of the system are divided into the students and teachers, the core function of the system is to collect the data which related to students' management and maintenance, so it is a structure of data-centered and it relies on data to link each module and coordinate work.

\section{B. The analysis of system function module}

- The main functions of the students' module are the appointment and the consultation: students make an appointment of the psychological consultation online, and fill in the corresponding information and select consultation date and then submit. Then the teachers check the appointment in the system daemons, and determine the time coordinated with the students and to accept an appointment date. The other functions are shown in Fig.1.

- The basic function of teachers' module is to look up for students' appointments: teachers view all acceptable time and those which are not being accepted, and check the appointment content and the students' information, 
then decide the final appointment date and submit it. During the process, teachers can coordinate the appointment time with the students, after successfully complete an appointment, the reservation record status will be changed to "true" which means to make an appointment successfully. The other functions are shown in Fig. 2.

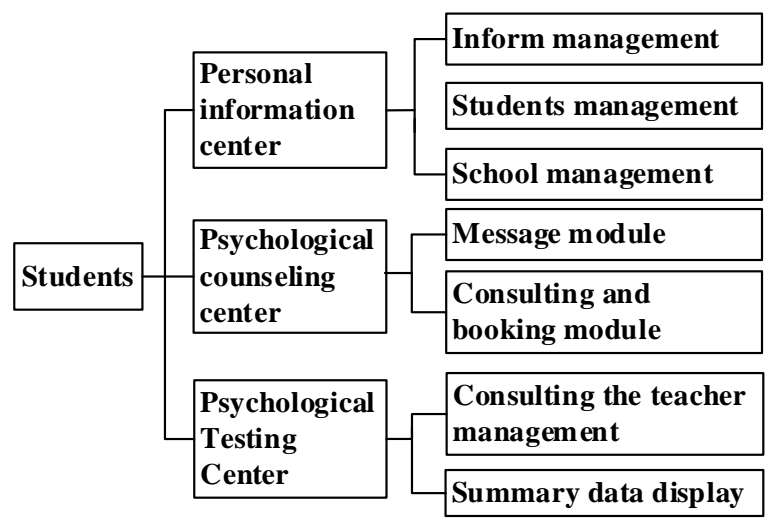

Fig. 1. The student basic function module diagram

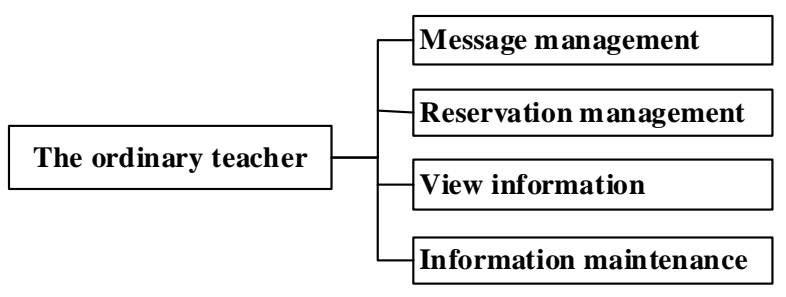

Fig. 2. The teacher basic function module diagram

- The super administrator is one of the teachers who have more authority; his main duty is to manage all the data, including the students information, teachers information psychological test information etc. The other functions are shown in Fig. 3.

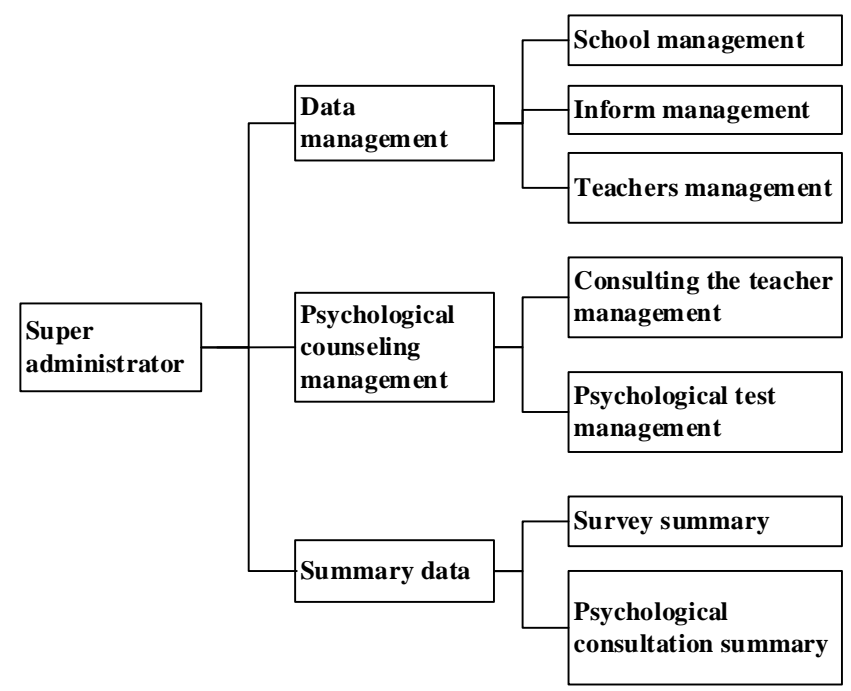

Fig. 3. The basic function module diagram of the super administrator

\section{SySTEM DESIGN AND REALIZATION}

There are two parts of this system: front part and back part. At front part, when the students log in, they have some authorities to do: maintain their basic information, change their password, browse the notices, take psychological tests, consult their questions, leave some messages online, and make an appointment etc. At back part, teachers those have limits of authority will answer the students' questions online, then accept the appointments and submit the right time. The other teachers who have more authority can manage all of the data; allocate permissions to other teachers, and summary the data etc.

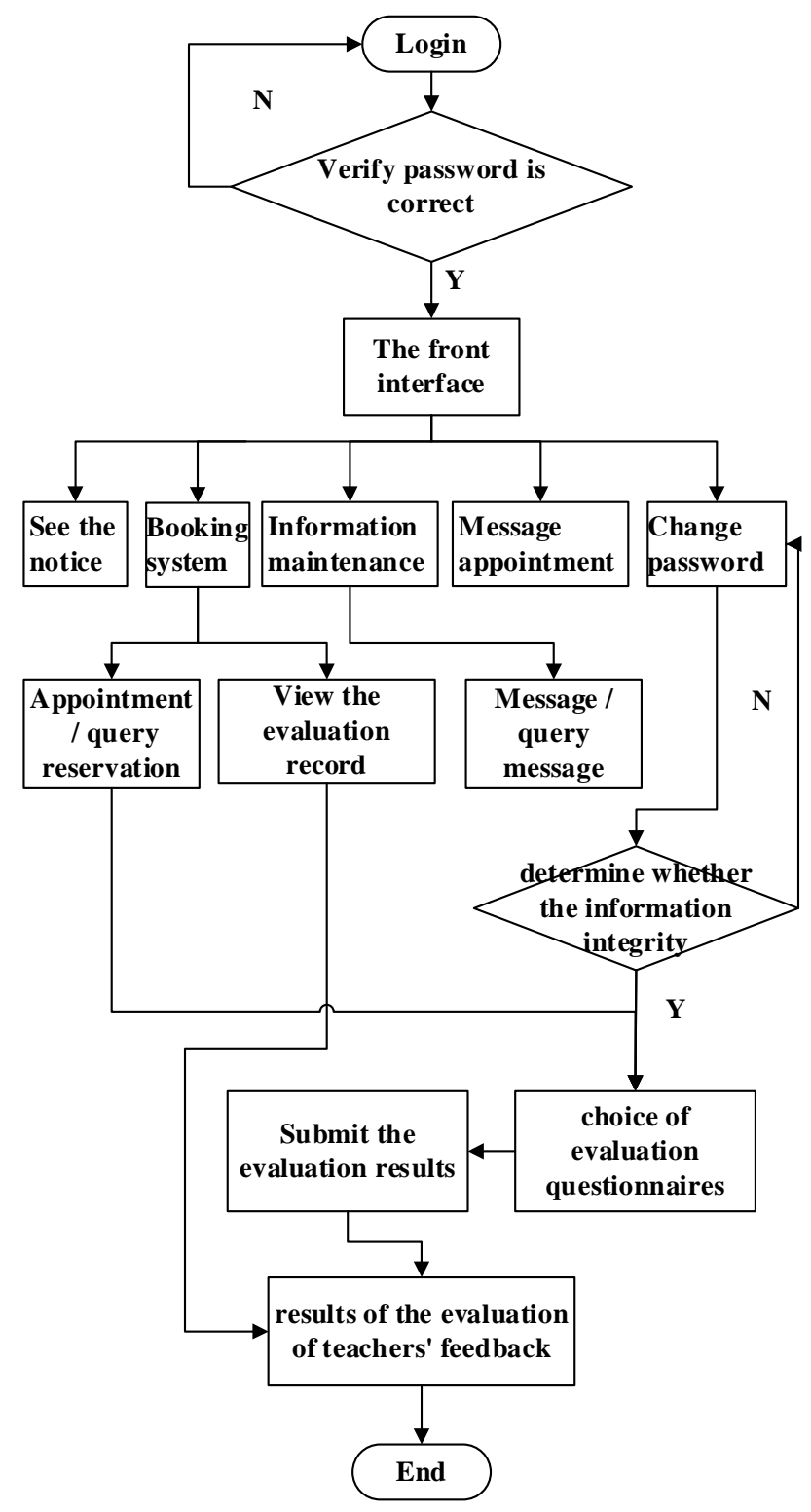

Fig. 4. Student operation flow chart

\section{A. The students'operation process}

After the students log in the system using the correct account, they can modify the password, maintain the information, browse the notice, and make psychological testing, as well as 
leave online message for consulting and make an appointment of psychological counseling and the other operations. The specific process is shown in Fig.4. The student processing interface is shown in Fig.5.

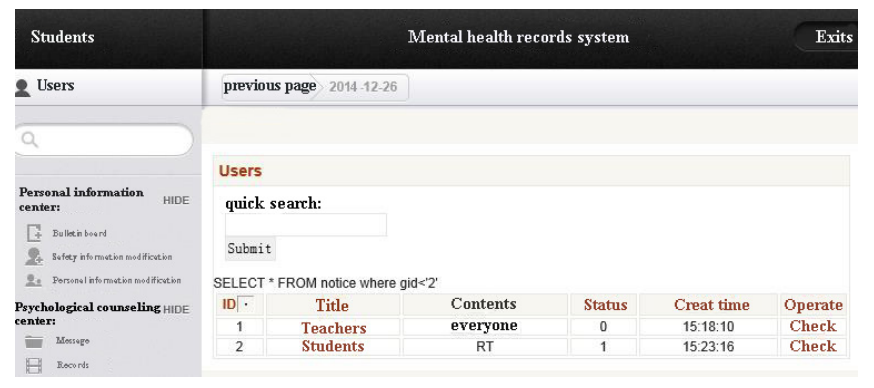

Fig. 5. Student processing interface

\section{B. The teachers'operation process}

The ordinary teachers make personal information maintenance in the back part. They reply to students' messages and accept the students' appointment, and check the appointment registration and so on. The interface of teacher appointment processing is shown in Fig. 6 . The detail flow chart is shown in Fig.7.

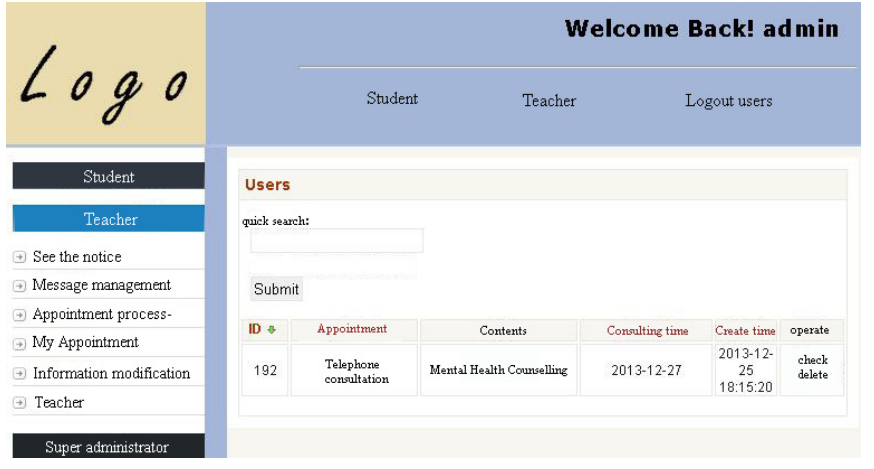

Fig. 6. Teacher appointment processing interface

\section{THE KEY TECHNIQUES OF THE SYSTEM}

The core process of the system is centering on the "data", so it is the most important that how to display the data more easily and how to reuse the data. The basic function is not only to show the multiple data through the paging technology, but also to sort them according to variable attributes. It needs have some operating navigations. Some pages should have function to add new data. So it will combine all of the above functions in one page. The followings are their realizations of those main functions: paging, searching and sorting.

\section{A. The realization of the function of data paging display}

- Using the label "Limit” to control the page links;

- Creating function "build_query( )": it defined a variable "\$cur_page" which is used to achieve the current page, a variable "\$results_per_page" which is used to show the results, a variable "\$skip" which is used to calculate the records of the previous pages, and a variable "\$total" which is used to store the searched total results, then obtain the total page “\$num_pages" which is the result of the "\$total" dividing the “\$results_per_page”;

- For the paged results to modify the query statements, on the premise of the calculated multiple pages, it generated the page navigation links, then called the function “generate_page_links()” to display.

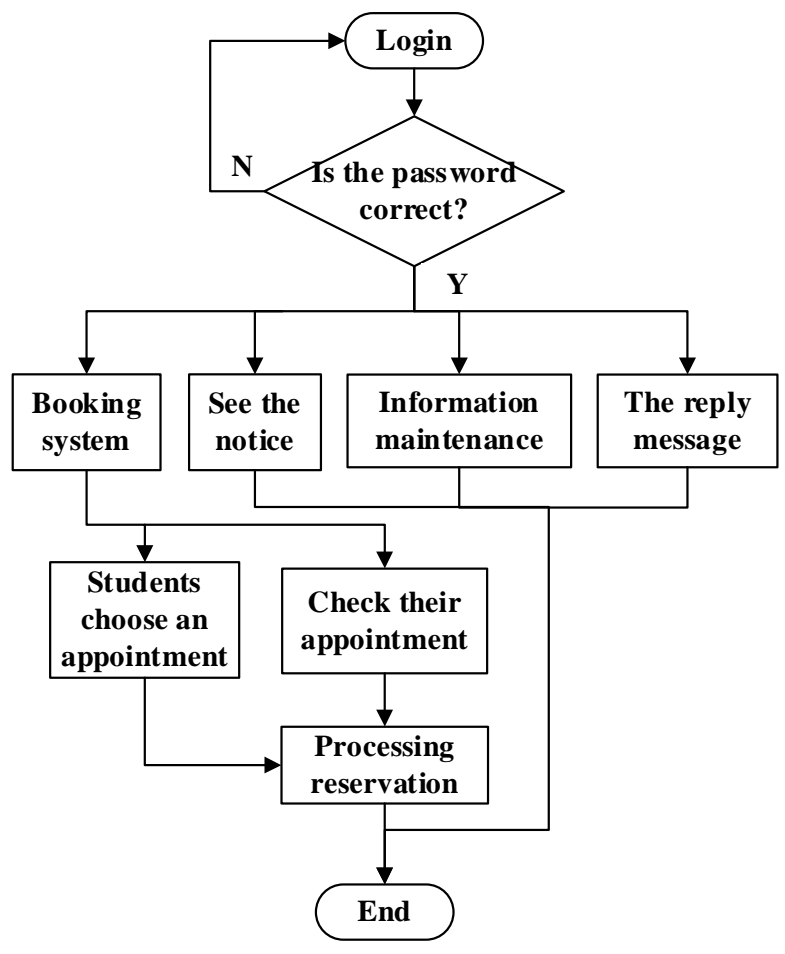

Fig. 7. The ordinary teacher's operation process

\section{B. Session and cookie}

Session is a method for holding the state based on Web server, allowing to keep any object during the user session through stored the object in memory of the Web server [5]. In PHP, the Session object is stored in the server, which is more relative safety and has not length limit like Cookie's, so its application is more widely, but the advantages of Cookie are also significantly, namely the Cookie exists much longer than the Session[6].Considering that many users login the system at home, in order to ensure the login more persistence, this system adopts the "Session adding Cookie" to store basic user login information, including its authority (the flow chart is shown in Fig. 8).

\section{CONCLUSIONS}

The students' psychological health guidance center is responsible for preserving and managing the psychological archives. Archives record the individual basic information of all the students, mental health status and various psychological tests results and individual counseling situation. Students can view the mental health files of individual on the web site. So they know themselves correctly through the system and face the reality and keep forging ahead positively. The mental 
health instructors can check the mental health records keeping secretly and better apply the health education to the students' service. In universities and colleges, if they can pay attention to the students' psychological health situation, comparing with traditional teaching, it is more useful to enhance the whole quality of the students' education.

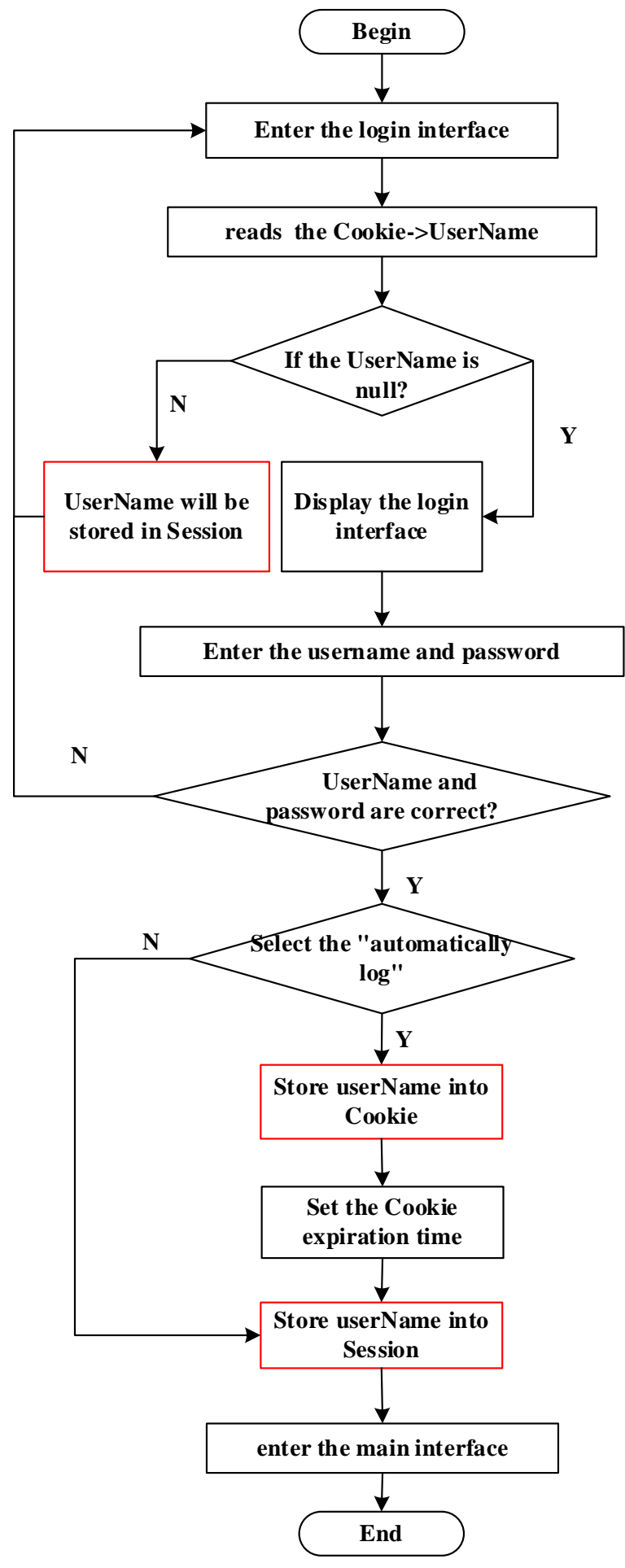

Fig. 8. Session+Cookie login process diagram
The students' psychological archives established by the psychology method make them to be more professional on identification and evaluation of records about the student's cognition process, intelligence status, characteristics and mental health status of personality. Establishing psychological archives to collect the data and evidence systematically, which is a process of describing and classifying students' psychology.

\section{ACKNOWLEDGMENT}

This research is financially supported by: The "521 personnel training plan" of Zhejiang Sci-Tech University, Applied Economics Research Base of Zhejiang Sci-Tech University (2016JYJG03), Project funded by China Postdoctoral Science Foundation and China Scholarship Council.

\section{REFERENCES}

[1] Han Xiangzhi. Suggestions for Improvement of Mental Health Records Management[J]. Management Engineer, 2014,19(4):53-55. (In Chinese)

[2] Wang Chunyan. College Students Mental Records Management[J].Beauty \& Times,2013,(6):118-118. (In Chinese)

[3] Gao Qun. College Students' Psychological Profile Management Model[J].Lantai World,2013,(26):72-73. (In Chinese)

[4] Dong Guiling, Wu Fuxuan, Li Yulin etc. The Contrast Study of Psychohealth Status between New Recruits and the Educating Students from one Medical College[J]. Journal of HEZE Medical College,2003,15(1):68-69. (In Chinese)

[5] Li Xiaoming. Java Web Technology Based Solutions to Problems Repeatedly Submitting Analysis and Applications[J].Computer Knowledge and Technology,2013,(35):7966-7967. (In Chinese)

[6] Yi Weihuan. The Comprehensive Application of Session and Cookie on the System Log in[J].Computer Soft ware and Applications,2013,(18):5152. (In Chinese) 